\title{
Dor que Fala, Dor que Cala: Sentidos da Dor Para Usuários da Atenção Primária
}

\author{
Pain that Speaks, Pain That Silences: Meanings of Pain for Primary Health Care Users \\ Dolor que Habla, Dolor que Calla: Sentidos de Dolor Para Usuarios de Atención Primaria
}

\author{
Josenaide Engracia Santos ${ }^{1}$ \\ Universidade de Brasilia (UnB) \\ Rozemere Cardoso Souza \\ Universidade Estadual de Santa Cruz (UESC)
}

\begin{abstract}
Resumo
Introdução: A dor pode ter origem cognitiva, fisiológica, comportamental, bem como pode estar associada a fatores culturais e educacionais na percepção da dor. Objetivo: Compreender os sentidos atribuídos à dor por pacientes da atenção primária à saúde. Método: Estudo qualitativo. Foram recrutados 20 pacientes com idade entre 30 e 65 anos que se queixavam de dor. Realizamos entrevistas individuais usando questões norteadoras. A análise foi realizada por meio do mapa de associação de ideias. Resultados e discussão: As categorias identificadas foram: dor como experiência singular e recursos para alívio da dor. Os participantes revelaram nas narrativas: as mulheres falam da dor de forma indiferenciada, difusa e inominável; já nos homens a dor é palpável, mensurável e objetiva. Os recursos utilizados pelas mulheres para aliviar a dor são os psicofármacos e os homens utilizam o autocontrole da vida cotidiana. Conclusão: É importante que os profissionais sejam mais sensíveis às pessoas e aos significados que elas atribuem à sua dor e às suas reais necessidades. Todavia, vale ressaltar que, em uma situação em que a mente não aceita a dor e conflitos, para ambos os sexos, o corpo responderá de forma e sentidos implacáveis explicitados na fala ou no silêncio.

Palavras-chave: dor, atenção primária à saúde, sofrimento humano
\end{abstract}

\begin{abstract}
Introduction: Pain may be of cognitive, physiological, or behavioral origin, and it may be associated with cultural and educational factors in pain perception. Objective: To understand the meanings attributed to pain by patients of primary health care. Methods: Qualitative research. Twenty patients aged between 30 and 65 who complained of pain were recruited. We have conducted individual interviews using guiding questions. The analysis was carried out through an idea association map. Results and discussion: We identified the following categories: pain as a personal experience and approaches for pain relief. The participants revealed in the narratives that women address pain in an undifferentiated, diffuse, and nameless way; in men, pain is palpable, measurable, and objective. The procedures used by women to relieve pain are psycho-pharmaceuticals, and men use the self-control of everyday life. Conclusion: Professionals must be more sensitive to people and the meanings they associate with their pain and their real needs. However, it is worth pointing out that, in a situation where the mind does not accept pain and conflicts, for both sexes, the body will respond in relentless ways and senses expressed by speech or by silence.

Keywords: pain, primary health care, human suffering
\end{abstract}

\section{Resumen}

Introducción: El dolor puede tener un origen cognitiva, fisiológica, conductual, así como puede estar asociado con factores culturales y educacionales en la percepción del dolor. Objetivo: comprender los significados atribuidos al dolor por los pacientes de atención primaria de salud. Método: Estudio cualitativo. Se reclutaron 20 pacientes con edad entre 30 y 65 años que se quejaban de dolor. Realizamos entrevistas individuales, utilizando preguntas orientadoras. El análisis sucedió utilizando el mapa de asociación de ideas. Resultados y discusión: las categorías identificadas fueran: el dolor como una experiencia única y recursos para el alivio del dolor. Los participantes revelaron en las narrativas: las mujeres hablan del dolor de una manera indiferenciada, difusa e inmencionable; mientras que en los hombres el dolor es palpable, medible y objetivo. Los recursos que las mujeres usan para aliviar el dolor son las drogas psicotrópicas, ya los hombres usan el autocontrol de la vida diaria. Conclusión: Es

\footnotetext{
${ }^{1}$ Endereço para contato: Campus Universitário - Centro Metropolitano, Ceilândia Sul, Brasília-DF, CEP: 72220-275. Telefone: (61) 3107-8938. E-mail: josenaidepsi@gmail.com
} 
importante que los profesionales sean más sensibles a las personas y los significados que atribuyen a su dolor y sus necesidades reales. Sin embargo, es digno de mención que, en una situación en la que la mente no acepta el dolor y conflictos, para ambos sexos, el cuerpo responderá de manera implacable y los sentidos se harán explícitos en el habla o el silencio.

Palabras clave: dolor, atención primaria a la salud, sufrimiento humano

\section{Introdução}

A dor se apresenta ao homem de maneiras variadas e também inesperadas, impondo-se sem o controle da vontade, integrando os seres humanos numa experiência única em que o corpo é o centro das atenções. Nos últimos anos, um grande número de pacientes tem procurado atendimento no cenário da atenção primária com um conjunto de sintomas, relacionado a dores em diversas partes do corpo.

Muitos se queixam de dor na cabeça, nas costas, no peito ou no estômago. Pode-se dizer que é a dor que insiste em falar, e há os pacientes que se calam quando a dor se materializa no corpo, não na fala. Conforme Angerami-Camon (2012), é a dor sentida e vivida na dimensão corporal que pode ser resultado de lesão, dano ou ferimento, conduzindo a uma sensação de calor, frio, pressão, corrente elétrica e irritação física. A dor divide a unidade, rompe o habitual da existência, produz a descontinuidade; é o ruído na vida silenciosa dos órgãos (Mendes, 2012). Diferentemente de outros sistemas, o sistema sensorial para a dor é extremamente amplo; uma sensação dolorosa pode ser iniciada em qualquer parte do corpo, aspecto comum vivenciado na clínica médica no contexto da atenção primária.

O Instituto de Medicina dos Estados Unidos considera a dor como problema de saúde pública (Von Korff, Dworkin, \& Le Resche, 1990). Todavia, apesar de considerada um problema de saúde frequente, pouco se conhece sobre a dor a partir de pesquisas que tratem da percepção do usuário sobre a dor, uma experiência rica e multidimensional que varia tanto em qualidade quanto em intensidade, assim como em características afetivo-motivacionais. Estudos como esses, que pesquisam vários aspectos da dor, permitem visão mais ampla do fenômeno e fornecem subsídios para o planejamento de ações preventivas.

A dor pode ser uma experiência universal, mas também é experiência singular, pois se multiplica em experiências, vivências e representações muitas vezes inefáveis, que escapam frequentemente da avaliação objetiva, principalmente em unidades de cuidados primários de saúde (Leão, 2002). Ela pode gerar incapacidade e diversos sofrimentos representados pelo impulso nociceptivo, lesão prévia e inflamação (Von Korff et al., 1990). É a dor e o agravamento dos sintomas a ela associados que levam o paciente à procura de ajuda, mesmo quando ele não tem consciência de que deve procurar um médico.

A dor tem dimensões corporais, psicológicas e socioculturais. Ela é definida como um processo resultante de uma percepção somatossensorial, presente no cérebro como uma imagem mental e seguida por uma desagradável emoção, bem como mudanças no corpo (Bueno-Gomez, 2017). A dor, quando identificada no corpo, especificamente em circunstâncias biológicas ou observáveis, movimenta as pessoas em busca de serviços de saúde, principalmente na atenção primária, por ser a porta de entrada para as demandas.

Os serviços de saúde de Atenção Primária à Saúde (APS) e de pronto atendimento constituem locais em que os usuários costumam buscar ajuda para queixas somáticas (Fonseca, 2006), muitas vezes retratadas como dores, fenômeno também conhecido como 
somatização, associado a um estado de mal-estar generalizado, dores pelo corpo, dor no peito e ansiedade (Takadoro, 2012).

A APS é porta de entrada não apenas para a rede de serviços de saúde, mas também para a variedade de demandas; e a dor, para Ruviaro e Fillipin (2012), é uma das causas mais comuns para busca por auxílio médico, que na maioria das vezes vem com características variadas, muitas vezes em forma de dor de cabeça, coluna, articulações, estômago, peito, palpitação e/ou dor generalizada no corpo.

Em estudo realizado por Siqueira (2013), a prevalência de dor foi de 30\% na atenção básica. É um sintoma referido pelos pacientes, por isso a importância do diagnóstico e tratamento na APS é fundamental, evitando os outros níveis mais complexos de atenção à saúde (Ruviaro \& Fillipin, 2012).

No horizonte dessas colocações, propôs-se este estudo a fim de responder às seguintes perguntas norteadoras:

- Qual(is) o(s) sentido(s) atribuído(s) à dor por usuários da APS?

- Como as pessoas nomeiam e como lidam com a dor?

É no percurso desses questionamentos que compreender a dor que fala e cala pareceu-nos necessidade eminentemente clínica, oriunda da experiência com pacientes da APS e da necessidade de diálogos que permitissem entender e acolher as diversas expressões e os sentidos que os usuários atribuem à dor. Assim, este estudo tem o objetivo de compreender os sentidos atribuídos à dor por usuários da APS, na cidade de Ceilândia, Distrito Federal (DF), Brasil.

\section{Método}

Foi realizado um estudo qualitativo e, para tanto, optou-se pelo referencial teórico-metodológico do construcionismo social, que é, sobretudo, uma abordagem teórica da Psicologia Social. O construcionismo concebe o discurso sobre o mundo como um produto da interação social. Um empreendimento coletivo interativo, que ocorre por meio das dinâmicas das relações sociais, econômicas, históricas e culturais (Spink, 2013). O construcionismo constrói-se por meio das interações diárias entre as pessoas, no decurso da vida. Por isso, todo tipo de interação social, particularmente a linguagem, é de grande interesse para os pesquisadores que trabalham com o construcionimo social.

Esta pesquisa foi realizada na cidade de Ceilândia, Distrito Federal, Brasil, em cenários da Estratégia Saúde da Família (ESF), em que se realizavam atividades práticas de estudantes da Universidade de Brasília (UnB).

Os participantes da pesquisa foram 20 (vinte) usuários de ambos os sexos, que atenderam aos seguintes critérios de inclusão: ter idade superior a 18 anos, concordar em participar da pesquisa de forma voluntária e apresentar vinculação com o problema investigado. 0 recrutamento dos participantes foi realizado com a colaboração dos profissionais de saúde, enfermeiros, médicos e assistente social. Um dos critérios foi: pacientes com mais queixa de dores em busca de assistência médica. Este último critério baseia-se na amostra do tipo teórica ou intencional, bastante utilizada em pesquisas com abordagem qualitativa, nas quais os participantes são escolhidos por sua relevância ante o objeto, com vistas a dar conta das questões que a investigação orientada pelo marco teórico da pesquisa procura investigar (Augusto, Souza, Dellagnelo, \& Cario, 2013). 
O critério de exclusão foi a presença de comprometimento físico e/ou mental que impossibilitasse a participação: basicamente, surdez, retardo mental e demência (diagnosticados previamente em parceria com a equipe).

\section{Procedimentos de Coletas de Dados}

A realização das entrevistas com os usuários ocorreu de maio de 2013 a fevereiro de 2014, com a participação dos enfermeiros das unidades da ESF. Estes escolhiam e convidavam os usuários com queixas de dor e os encaminhavam para o consultório onde se encontrava a pesquisadora, que os esclarecia sobre a pesquisa e o sigilo, bem como a necessidade de assinatura do termo de consentimento informado. Após a assinatura do termo, dava-se início à entrevista no consultório das unidades da ESF, definido para este fim a fim de evitar interrupções e garantir a privacidade.

A entrevista é do tipo semiestruturada, composta por duas partes: uma para caracterizar os indivíduos (sexo, idade, raça/etnia e ocupação); outra, no que tange ao sentido atribuído a dor. A questão norteadora foi a seguinte: o que a palavra dor Ihe lembra ou sugere? A entrevista visava à profundidade e não diretividade; e, também, o diálogo com o participante dentro de um contexto descontraído, em que se propiciava o máximo de liberdade de expressão. Todas as entrevistas foram gravadas num tempo estimado de 30 minutos, com apenas um encontro para sua realização.

\section{Procedimentos de Análise de Dados}

Os conteúdos emergentes das entrevistas foram transcritos, respeitando-se a sequência da enunciação, em colunas correspondentes às categorias descritivas que emergiram dos objetivos da pesquisa e da leitura da própria entrevista (Pinheiro, 2013). Esse mapeamento corresponde à técnica denominada de "Mapas de Associação de Ideias", que "[...] são instrumentos de visualização do processo de Interanimação que possibilitam, entre outras coisas, mostrar o que acontece quando perguntamos certas coisas ou fazemos certos comentários" (Spink, 2013, p. 38). Colabora no processo de interpretação e comunicação dos passos subjacentes: a identificação dos repertórios interpretativos (seguida de uma breve análise sobre o uso deles durante a entrevista) e a síntese temática dos sentidos produzidos do conjunto das entrevistas.

Os repertórios são definidos como o "conjunto de termos, descrições, lugares-comuns e figuras de linguagem que demarcam o rol de possibilidades de construções discursivas, tendo por parâmetros o contexto em que essas práticas são produzidas e os estilos gramaticais específicos".

A construção dos mapas organizou-se a partir de categorias com base no objetivo do estudo, preservando a sequência das falas (Spink \& Medrado, 2013). Essa técnica envolve os seguintes passos:

a) um processador de dados tipo Word for Windows, para digitar toda a entrevista;

b) construir uma tabela com números de colunas correspondentes às categorias utilizadas; e

c) utilizar as funções de cortar e colar para transferir o conteúdo do texto para as colunas, respeitando-se a sequência dos diálogos (Spink \& Lima, 2013). 
As categorias utilizadas para os mapas neste estudo foram: como nomeia a dor, como a descrevem, como explicam a dor, o que dizem sobre as práticas de alívio ou solução da dor.

Após análise dos mapas, fez-se a síntese temática dos conteúdos emergentes das entrevistas a partir do entrelaçamento de quatro aspectos:

a) o uso dos repertórios interpretativos sobre os sentidos da dor e sobre as práticas de alívio e manejo da dor utilizadas (e que se constituem dos conteúdos dos mapas de associação de ideias);

b) a literatura investigada durante a pesquisa;

c) o referencial teórico-metodológico; e

d) a interpretação das pesquisadoras.

\section{Procedimentos éticos}

A pesquisa obedeceu às normas e diretrizes que regulamentam a pesquisa que envolve seres humanos do Conselho Nacional de Saúde, Resolução n. 466, de 12 de dezembro de 2012. A pesquisa foi autorizada pelo Comitê de Ética em Pesquisa, da Fundação de Ensino e Pesquisa em Ciências da Saúde (Fepecs), sob o número 239.576/2013.

\section{Resultados}

Os participantes apresentavam as seguintes características sociodemográficas:

Dez mulheres - uma de 30 anos, recepcionista, identificava-se como branca e tinha ensino médio; três de 47 anos, donas de casa, identificavam-se como brancas e tinham ensino fundamental; três entre 50 e 57 anos, diaristas, identificavam-se como pardas e tinham ensino fundamental; duas de 59 anos, donas de casa, identificavam-se como brancas e eram analfabetas; e uma de 60 anos, dona de casa, identificava-se como branca e sabia ler e escrever.

Dez homens - cinco entre a faixa etária de 58 e 60 anos, pedreiros, autodeclaravam-se brancos e tinham ensino fundamental; dois de 65 anos, aposentados, autodeclaravam-se brancos e tinham ensino fundamental; um de 29 anos, cantor sertanejo e repositor, autodeclarava-se branco e com ensino médio; e dois de 45 anos, vigilantes e porteiros, autodeclaravam-se pardos e tinham ensino médio.

Os múltiplos sentidos produzidos nos conteúdos emergentes das falas dos participantes foram descritos em categorias temáticas, explicitadas segundo os sentidos da dor para muIheres e para os homens e, também, conforme o manejo da dor no cotidiano desses participantes, descritos a seguir.

\section{Sentidos da Dor para as Mulheres}

Os sentidos da dor para as mulheres foram descritos a partir das seguintes categorias temáticas:

a) dor como experiência singular;

b) dor como sofrimento psíquico e limitação; e

c) manejo da dor no cotidiano da APS.

Dor como experiência singular. Neste tema, a nomeação da dor está associada à subjetividade como metáfora principal. A dor revelou-se como singular para quem a sente, uma 
experiência humana compartilhada em seu significado, relacionado aos aspectos psíquicos, na forma como se sente e se vivencia. Essa nomeação sinaliza a dor como experiência também corporal, na qual se agrega a descrição dos sentimentos. Existe estreita relação entre a dor, o medo e as experiências de ansiedades subsequentes (Fleming, 2003).

A dor deixa você depressiva. (E7)

Angustiante. Incomodante. (E3)

A dor é um fenômeno que inclui tanto a nocicepção - "o mecanismo envolvido na recepção de estímulos dolorosos" - quanto o significado para essa sensação. Giordano (2008) reconhece a universalidade da nocicepção, mas não considera essa como dor; para ele, a dor inclui o significado que os sujeitos atribuem à nocicepção, e esse significado muda de cultura para cultura, de pessoa para pessoa. Em exemplo dos comentários a seguir, tal conceito é explicitado na forma de demanda, queixa ou clamor:

Dor é triste, insuportável, é muito ruim. (E1)

Muito horrível. Dor insuportável. (E6)

Dor como sofrimento psíquico e limitação. A experiência do sofrimento pode ter um elemento verdadeiramente subjetivo. Neste tema, foram agrupados repertórios que explicitam a dor como dor psíquica e como o conjunto de sintomas do que se nomeia de "nervoso", sendo esses sentidos entendidos aqui como indissociáveis da dor corporal:

Dor é angústia. (E10)

Dor na alma. (E4)

Ansiedade. (E8)

A dor provoca o grito, o gemido; a palavra aí não tem efeito. A dor altera o laço social, modifica as relações com o mundo e só consegue se expressar no corpo por meio de sensações e inquietações, boas ou ruins, como angústia, ansiedade, irritação, estranheza, tensão nervosa e humor deprimido. A dor enfatiza bastante a relação entre corpo e sofrimento, com implicações características de depressão e de tensões no cotidiano das participantes:

Parece um tipo de depressão. . . passa o dia todinho no sofá. (E9)

[. . .] alguma tensão nervosa. (E10)

A tensão nervosa é um repertório rico, utilizado para expressar tanto desordem emocional quanto tensão somatizada. É como se estivesse, permanentemente, reafirmando a desorientação:

Perturbação, perturbação. (E5)

Crise de choro que tem a ver com dor no peito, na cabeça, nos peitos, e agonia na cabeça. (E2)

Dor nos peitos, cabeça, na testa, ai é tipo um cansaço nos peitos, aumenta o cansaço e aumenta a angústia nos peitos, e aí vem a crise de choro. (E9)

Fibromialgia que endurece os nervos da gente, dor no corpo todo, bico de papagaio e artrose. (E8) 
Sinto muita dor nos braços e dor nos nervos, da cabeça, estômago, tenho falta de ar. (E7)

Nesse contexto, a dor traz implicações aos diversos aspectos da vida diária e provoca sofrimnto limitante no dia a dia, inclusive nas atividades laborais.

E descobri que tenho problema na coluna não consigo gomar roupa, não consigo limpar casa, não consigo passar, você não consegue e não tem condições, não tem condições de lavar a louça, a máquina lava roupa, mas você não consegue estender, dá dor no peito, cansaço. (E2)

Manejo da dor no cotidiano da APS. Os sentidos produzidos acerca do manejo da dor na APS foram mais explicitados pelas intervenções medicamentosas e práticas corporais. A prescrição medicamentosa de psicofármacos se caracterizou como recurso mais utilizado na atenção primária para as mulheres participantes deste estudo:

O clínico-geral me passou Fluoxetina. . que eu não dormia. (E1)

Ele passou Valium e tinha outro que não me lembro-me do nome [. . . ] a tomar uma caixa de Lorium. Nunca mais fiquei mal. (E8)

O medicamento parece uma alternativa de resultado rápido, ou seja, pode servir para silenciar o mal-estar da existência humana, a exemplo da tensão e das dores propriamente ditas:

Tomo um calmantezinho [medicamento], tomo Rivotril, foi a médica neurologista que passou, e Maracujina Dorilax e Ibuprofeno uma vez ou outra, relaxante muscular de um dia para outro dá uma melhorada, e uso medicamento para aliviar a tensão. (E2)

Tomo Diazepam, Omeprazol. Tomo Diazepam, às vezes ataca problema de pressão e às vezes ataca problema psicológico. O medicamento é a chave. (E4)

Essa concentração de sentidos no corpo leva a um intenso processo de medicalização. Conforme Tesser (2006), são as duas faces da mesma moeda, pelas quais se incide sempre sobre o corpo como o foco do mal-estar, em que os psicofármacos se apresentam no registro do uso e da prescrição pelos médicos. As falas a seguir servem de exemplo:

Tomo remédio controlado, o médico passou para mim o Rivotril. Quando estou sentindo muita dor e insônia e ansiedade, eu tomo. (E6)

Para aliviar a dor, tomo Paracetamol, Neosaldina e tomei durante muito tempo o Rivotril.

Nessa perspectiva, as narrativas apresentam o medicamento como recurso principal e sinalizam que a conduta mais frequente dos médicos em relação à dor é a prescrição com benzodiazepínicos e antidepressivos, como coadjuvante da terapia analgésica:

Tomei também Amitriptilina, mas não me dei bem; falei com Dr. X que fiquei muito preguiçosa, e foi modificado para Diazepam. Eu só venho no médico quando acaba o Diazepam. Pego a receita aqui. (E9)

Tomo duas Fluoxetinas, estou desinchando, e as pessoas acham que o problema é do corpo, e não é da mente. (E1) 
O alto índice de prescrição de antidepressivos e ansiolíticos benzodiazepínicos pode ser justificado pelo fato de a fluoxetina ser classificada como inibidor seletivo da receptação de serotonina, classe de antidepressivos mais seguros e tolerados. Não obstante, destaca-se que todos os antidepressivos e ansiolíticos benzodiazepínicos prescritos consistem em medicamentos distribuídos pelo Sistema Único de Saúde, o que poderia fomentar sua prescrição em relação a outras opções (Milos et al., 2013).

Outra prática usual das mulheres para manejo da dor foi descrita por atividade física e de relaxamento corporal:

Caminhada... vou para hidroginástica e na água começa a mexer e melhorar e [. . . ] tem uma esperança para dor - tem muita gente com esse problema - e o pilates. (E6)

Relaxamento do corpo. . faço no posto, ajuda muito; e caminhada duas, três vezes por semana. (E7)

\section{Sentidos da Dor para os Homens}

Os sentidos da dor para os participantes deste estudo foram descritos a partir dos seguintes temas:

a) dor como sinal de alerta;

b) dor como incapacidade;

c) dor como ameaça à integridade física e à saúde mental;

d) a dor negada; e

e) recurso para aliviar a dor no cotidiano da APS.

Dor como sinal de alerta. As nomeações explicam a dor como sinal de alerta, relacionado a possível dano, podendo manifestar-se de forma involuntária e voluntária:

A dor é um susto, né? (M8)

A dor é um alarme quando o organismo não está bem. (M9)

Assim nomeada, a dor é útil para indicar manejos necessários à prevenção de algum dano ou perda possíveis.

Dor como incapacidade. Outra nomeação é o termo "incapacitante", que interrompe a naturalidade dos fatos, o que marca a experiência da dor é a ruptura com a vida cotidiana, conforme relato a seguir:

Dor. . . é a pessoa [. . .] não ter o mesmo sentido do movimento. Não poder fazer a mesma coisa que poderia fazer sem ela, estar desabilitada naquela hora, um ferimento, alguma coisa assim, dor de cabeça. (M1)

Então essas são as dores insuportáveis, né? E você tá sujeito, eu estou sujeito, qualquer um. (M2)

Dor como ameaça à integridade física e à saúde mental. "[A] pessoa acredita que sua integridade física está em perigo" (Bueno-Gomez, 2017) e pode ser causada por outras experiências. No relato masculino, a dor é relacionada ao sofrimento, sendo considerada estado de angústia vinculado à situação na qual os sujeitos percebem como ameaça à própria integridade; relacionada a componentes psíquicos e sociais, na forma como se 
sente e se vivencia. A dor física pode se transformar em dor moral e, desta, em sofrimento psíquico:

Coisa ruim, algo que não desejo pra ninguém. Sofrimento, né? De uma certa parte. (M3)

Tristeza, né? Dor é angústia, né? Um pouco de tristeza também. (M4)

A dor é um elemento do construto social, ou seja, produzido socialmente e incorporado em situações particulares do mundo masculino. A linguagem utilizada pelos homens para descrever essa experiência refere-se a uma lesão tecidual e a um estímulo neurofisiológico nociceptivo associados a alterações anatômicas ou cinesiológicas decorrentes de trauma, categoria que sintetiza a expressão da dor relacionada a questões físicas:

Como cicatriz, muita quebra de braço. (M1)

Você pode ver que, quando você cai de uma certa altura, a dor é tanta que você não consegue assim. . . se locomover, você não consegue agir, porque a própria dor não permite. (M10)

Teve uma vez que no trabalho eu mutilei um dedo, e dessa vez foi muita dor, e fiquei. . . Eu tenho lembrança de dor só dessa vez. Foi forte. (M3)

Porque eu estou sentindo uma dor aqui atrás do ouvido [. . . ] Dói o olho aqui e essa parte quase toda assim. Mas é todo dia, e às vezes dói o dia todo também e não passa. (M5)

A dor negada. Neste tema, estão agrupados os sentidos da dor que descrevem dificuldades dos homens em verbalizar o que sentem, pois falar de problemas de saúde pode significar possível demonstração de fraqueza, de feminilização perante os outros. O depoimento que segue é ilustrativo:

Dor. . . eu não sei dizer, porque eu não sou de sentir dor! Agora, aquela mulher minha lá, ela que sente dor no corpo direto. (M7)

A dor organizada pelos homens é ordenada nas relações sociais em que eles têm a representação da coragem e da razão.

Eu, graças a Deus, quase não passo dor. . às vezes tenho dor na cabeça e dor na coluna. Problema de coluna. (M4)

Se eu disser que não sinto. Por isso eu tenho medo, porque o pessoal diz que quem não sente dor é que tá sujeito a morrer daqui pra ali. Não sinto dor nenhuma. Graças a Deus! Não sinto dor nenhuma. (M2)

Não são dores muito fortes, não. (M8)

Esse negócio de dor assim é difícil. Dor nas pernas eu não tenho, nem dor nas costas. (M9)

Chama atenção o modelo de masculinidade que desqualifica e nega, no caso dos homens, determinados carecimentos do corpo:

Bom, eu acho que é pela idade e pelo desgaste dos ossos. Porque ele ataca mesmo no início, né? Porque já teve crises, né? Mas hoje não. Hoje está normal, mas, se eu caminhar muito, sente aquela. . assim dor no joelho. (M4) 
Porque às vezes o organismo reage em circunstâncias de desequilíbrio, né. . às vezes a gente come mal, se alimenta mal. Todas elas têm uma origem, elas não vêm por acaso. Ela se manifesta porque, conforme eu já falei, por razão de desequilibrio do organismo. (M9)

Recurso para aliviar a dor no cotidiano da APS. Quando se perguntou "O que você faz quando você está com dor?", foi evidenciado que, além do uso de medicamentos (não psicofármacos) ou do chá, os homens descrevem como recursos para lidar com a dor a atenção e o autocontrole:

Eu me tranquilizo muito, eu não deixo. . . a dor tomar conta de você completamente, né? Tento relaxar o máximo e tal, mas não uso medicamentos, né? (M1)

Primeiro, não deixo a dor tomar conta de mim, tento fazer pensar menos nela. Quanto menos pensar nela, menos dor eu sinto, é o que eu penso pra mim mesmo. (M2)

Para os homens, suportar a dor em silêncio também parece ser característica de força e virilidade:

Com a dor ninguém acostuma, mas que eu tinha que aprender a viver com ela na perna toda, então eu não. . Às vezes eu conversando com vocês aqui e agorinha estava doendo, latejando, doendo, doendo, mas aprendi já conviver com ela. (M5)

Sobre uso de medicamentos, a ênfase das narrativas foi dada à procura e à prescrição do médico. Por meio do médico, tem-se acesso a exames, medicamentos e efeitos terapêuticos:

Os medicamentos são recomendados pelo médico, pela medicina, né? Porque os médicos têm conhecimento, né. (M9)

Às vezes eu já vim pra arrecadar medicamento pra um sintoma que eu tenho que é gastrite. Que é dor também: às vezes recorro aos analgésicos, né? Que pode ser Dipirona e esses outros. E acaba passando. (M3)

Tomando remédio, eu tomo remédio de manhã cedo de jejum, tomo meio dia, tomo de noite. Eu não tomava nada disso. Quando eu tomo um Paracetamol, Dipirona ou alguma coisa vai indo e passa. (M6)

Eu fiz tratamento com médico. (M8)

O tratamento médico é procurado em quase todos os relatos e traz para os informantes dois elementos de fundamental importância:

1) o médico é quem pode, por meio de exame, determinar a existência ou não de uma entidade patológica e localizar, no corpo do doente, a fonte do problema; e

2) é o médico que fornece os remédios destinados a curar ou manter sob controle o paciente.

\section{Discussão}

Os múltiplos sentidos atribuídos à dor pelos participantes deste estudo descrevem formas distintas de nomeações, de explicações e de manejo da dor para homens e mulheres. Essas formas estão relacionadas às metáforas do corpo e da alma, clivagem de gênero, implicações e práticas sociais do cotidiano dos participantes. 
O primeiro ponto a ser destacado é que a nomeação da dor para homens e mulheres se cria a partir de uma trama de eventos que envolvem o campo corpóreo e anímico e as clivagens de gênero que instituem formas muito distintas de nomear a dor. Quanto às mulheres, privilegia-se a subjetivação do sofrimento expresso pelo gesto ou pela linguagem que formam e que, enfim, dá as características de uma dor geradora de angústia (outra forma sendo ela a própria angústia) inaudita, intraduzível, inexprimível e perturbadora. É um sofrimento psíquico, uma dor mental que convoca silêncios, impressões, gestos corporais, coisas que estão lá (Fleming, 2003).

Os homens preferem nomear a dor de forma mais descritiva, supostamente objetiva perante o próprio discurso, quando sinalizam que a dor é um sinal de alerta, de desequilíbrio. A dor é uma tendência ao desarmônico e pode ser incapacitante, principalmente quando diz respeito ao trabalho, que representa a mais substantiva identidade do homem (Leão, 2002). Os afazeres cotidianos acrescentam características e papéis morais - ser chefe da família, marido, genitor - e garantem a identidade masculina; e a admissão da necessidade de assistência médica poderia pôr em risco o próprio trabalho.

As mulheres relatam a dor como difusa e indiferenciada no corpo, que provoca interrupção nas tarefas domésticas. Isto é uma sintomatologia frequente que se manifesta como problemas gastrointestinais, síndrome do cólon irritável, dor pélvica crônica e fibromialgia; e está presente sem quadro patológico confirmado, essas são condições predominantes nas mulheres. Já o homem relaciona a dor como experiência real, na mesma medida em que paradoxalmente a nega. As demandas referidas pelos homens são bastante específicas: dores, febres, contusões ou ferimentos, reforçando a dimensão simbólica produzida e partilhada socialmente (Schraiber et al., 2010).

A escolha de recursos terapêuticos utilizados de forma mais intensa para lidar com a dor entre as mulheres são os psicofármacos. Um estudo realizado em Minas Gerais identificou que as mulheres atendidas na atenção básica apresentam uso de farmacopsiquiátrico superior ao homem (Vidal et al., 2013). As mulheres consomem mais psicofármacos que os homens, o que reforça resultados de estudos prévios que também observaram um predomínio do sexo feminino em relação ao consumo desses medicamentos (Rocha \& Werlang, 2013).

A alta prevalência do sexo feminino no consumo de remédios psiquiátricos pode estar relacionada com a preocupação que as mulheres têm com a saúde, gerando, assim, maior procura por atendimento nos serviços de saúde. Além disso, elas têm mais facilidade para descrever seus problemas, aumentando a probabilidade de receberem prescrição de psicofármacos (Moura, Pinto, Martins, Pedrosa, \& Carneiro, 2016). Os medicamentos são inegavelmente eficientes, pois diminuem as sensações do sofrimento. Pode-se dizer que, ao diminuir e eliminar os sintomas, os medicamentos eliminam ou diminuem a dor, mas não o sofrimento (Arruda \& Bosi, 2017).

Os homens utilizaram estratégias centradas nos aspectos físicos, autocontrole e ampliação de mecanismos capazes de otimizar a tolerância e minimizar a sensação dolorosa. Os homens sentem alguma coisa e procuram medidas de tratamento alternativas, como tomar alguma medicação por conta própria ou tomar algum chá, utilizando-se da orientação de algum farmacêutico. Essas saídas encontradas pelo sexo masculino para melhorar a saúde são mais pontuais, não os fazendo perder tempo (Gomes, Nascimento, \& Araújo, 2007). 
Interessante destacar que, nas narrativas, do homem ou da mulher, temos sentimentos de tristeza, nervosismo, angústia, depressão, ansiedade e outros, aludindo a uma experiência subjetiva que faz parte da cultura de qualquer agrupamento humano. Não dá para imaginar um agrupamento sem tristeza, sem ansiedade, visto que não existe um mundo onde a melancolia e o desgosto não existam.

A dor é aqui explicitada por várias áreas: Antropologia, Psicologia e Medicina, entre outros saberes/fazeres produzidos nas práticas discursivas do cotidiano, ou seja, a dor não pertence a um campo epistemológico específico. Quando se fala em dor, não se fala de um corpo que sente e vive a dor, mas de um sujeito para quem ela se torna realidade ou realidades, com implicações sociais, por vezes, geradoras de problemas nas relações conjugais, familiares e profissionais; em questões de gênero e em trocas sociais diversas (Takadoro, 2012). Isso contribui substancialmente para o esclarecimento das dimensões culturais, sociais e cognitivas da dor.

Todavia, o campo simbólico, subjetivo e significativo das dimensões da dor e do sofrimento ainda não é levado em consideração nos serviços de saúde. Consequências práticas e epistemológicas negativas de tal abordagem são a impossibilidade ou dificuldade de identificar e gerenciar, nessas dimensões de dor e sofrimento, a cura, a informação, a prevenção (Bueno-Gómez, 2017).

Os estudos limitam-se a supor que as mulheres utilizam mais psicofármacos, (prescritos), e que os homens utilizam mais autocontrole, o que os favorece por mantê-los por mais tempo afastados do tratamento médico. Ignora-se que a trajetória percorrida pelo paciente, desde o momento em que a dor começa a se mostrar problemática até a busca de ajuda institucional (médica ou não), não é linear; ao contrário, a trajetória mostra-se frequentemente um labirinto, com muitas idas e voltas para serviços de saúde que não foram relatadas na pesquisa.

\section{Considerações Finais}

O estudo atingiu os objetivos ao demonstrar que os sentidos atribuídos à dor estão relacionados a um não dito à procura de ser dito; a um indivisível, entre o binômio somático e psíquico, tanto entres homens quanto em mulheres. Apesar de mulheres e homens poderem ter relação similar com a dor, o fato de enfrentarem diferentes circunstâncias na APS leva-os, frequentemente, a tomarem decisões distintas devido ao seu repertório de opções, uma vez que, nos homens, o marcador é o autocontrole; e nas mulheres, os psicofármacos (recursos terapêuticos constantes).

Todavia, vale ressaltar que, numa situação em que a mente não aceita a dor e os conflitos, tanto para homens quanto para mulheres, o corpo responderá de forma implacável, falando ou calando. Recomenda-se que outros estudos investiguem a dor na atenção primária, buscando identificar fatores psicossociais que produzam riscos à saúde e à vida dos usuários, bem como reconceituar, em um amplo debate, a dor e o sofrimento. É importante que os serviços de cuidado primário sejam mais sensíveis às pessoas e aos significados que elas atribuem a sua dor, considerando a necessidade de prestar mais atenção às dimensões simbólicas subjetivas; e que os profissionais da APS sejam sensibilizados para serem mais empáticos com os pacientes e as reais necessidades destes. 


\section{Referências}

Angerami-Camon, V. A. (Org.). (2012). Psicossomática e a psicologia da dor (2. ed). São Paulo: Pioneira Thomson Learning.

Arruda, C. A. M., \& Bosi, M. L. M. (2017). Satisfação de usuários da atenção primária à saúde: Um estudo qualitativo no Nordeste do Brasil. Interface, 21(61), 321-332. doi: 10.1590/1807-57622015.0479

Augusto, C. A., Souza, J. P., Dellagnelo, E. H. L., \& Cario, S. A. F., (2013). Pesquisa qualitativa: Rigor metodológico no tratamento da teoria dos custos de transação em artigos apresentados nos congressos da Sober (2007-2011). Revista de Economia e Sociologia Rural, 51(4), 745-764. doi:https://doi.org/10.1590/S0103-20032013000400007

Brasil. (2012). Ministério da Saúde. Resolução CNS n. 466 (12 de dezembro). Disponível em: http://bvsms.saude.gov.br/bvs/saudelegis/cns/2013/res0466_12_12_2012.html

Bueno-Gómez, N. (2017). Conceptualizing suffering and pain. Philos Ethics Humanit Med, 12(7). doi:https://doi.org/10.1590/10.1186/s13010-017-0049-5

Fleming, M. (2003). Dor sem nome: Pensar o sofrimento. Porto, Portugal: Afrontamento.

Fonseca, M. L. G. (2006). Sofrimento difuso nas classes populares no Brasil: Uma revisão da perspectiva do nervoso. In Vasconcelos, E. M. (Org.), Abordagens psicossociais (Vol. 2, Reforma psiquiátrica e saúde mental na ótica (pp. 171-223). São Paulo: Hucitec.

Giordano, J. (2008). Maldynia:Chronic pain as illness, and the need for complementarity in pain care. Forsch Komplementmed, 15(5), 277-281. doi:https://doi.org/10.1159/000158572

Gomes, R., Nascimento, E. F., \& Araújo, F. C. (2007). Por que os homens buscam menos os serviços de saúde do que as mulheres? As explicações de homens com baixa escolaridade e homens com ensino superior. Cadernos de Saúde Pública, 23(3), 565-574. Recuperado de http://www.scielo.br/pdf/csp/v23n3/15.pdf

Leão, M. C. S. (2002). A dor como metáfora da unidade: O diálogo analítico entre o corpo e a psique (Dissertação, Departamento de Psicologia, Centro de Teologia e Ciências Humanas, Universidade Católica de Pernambuco, Recife, PE, Brasil). Recuperado de http://tede2. unicap.br:8080/handle/tede/166

Mendes, E. V. (2012). O cuidado das condições crônicas na atenção primária à saúde: O imperativo da consolidação da estratégia da saúde da família. Brasília: Organização PanAmericana da Saúde.

Milos, V., Rekman, E., Bondesson, A., Eriksson, T., Jakobsson, U., Westerlund, T., \& Midlöv, P. (2013). Improving the quality of pharmacotherapy in elderly primary care patients through medication reviews: A randomised controlled study. Drugs Aging, 30, 235-246. doi:https://doi.org/10.1007/s40266-013-0057-0

Moura, D. C. N., Pinto, J. R., Martins, P., Pedrosa, K. A., Carneiro, M. G. D. (2016). Uso abusivo de psicotrópicos pela demanda da estratégia saúde da família: Revisão integrativa da literatura. Sanare, 15(2), 136-144. Recuperado de https://sanare.emnuvens.com.br/ sanare/article/view/1048

Pinheiro, O. G. (2013). Entrevista: Uma prática discursiva. In Spink, M. J. (Org.), Práticas discursivas e produção de sentidos no cotidiano: Aproximação teóricas e metodológicas (pp. 156-187). São Paulo: Cortez. doi:https://doi.org/10.1590/S1413-1232013001100019 Rocha, B. S., \& Werlang, M. C. (2013). Psicofármacos na Estratégia Saúde da Família: Perfil de 
utilização, acesso e estratégias para a promoção do uso racional. Ciência \& Saúde Coletiva, 18(11), 3291-3300. doi:http://doi.org/10.1590/S1413-81232013001100019

Ruviaro, L. F., \& Filippin, L. I. (2012). Prevalência de dor crônica em uma Unidade Básica de Saúde de cidade de médio porte. Revista Dor, 13(2), 128-131. doi:https://doi.org/10.1590/ S1806-00132012000200006

Schraiber, L. B., Figueiredo, W. S., Gomes, R., Couto, M. T., Pinheiro, T. F., Machin, R., Silva, G. S. N., \& Valença, O. (2010). Necessidade de saúde e masculinidades: Atenção primária no cuidado aos homens. Cadernos de Saúde Pública, 26(5), 961-70. Recuperado de https:// scielosp.org/pdf/csp/2010.v26n5/961-970/pt

Siqueira, J. T. (2013). A dor dos brasileiros: Discutindo o uso de opioide no tratamento da dor no Brasil. Revista Dor, 14(4), 237-238. Disponível em http://www.scielo.br/pdf/rdor/ v14n4/en_v14n4a01.pdf

Spink, M. J. P. (2013). Linguagem e produção de sentidos no cotidiano. Rio de Janeiro: Centro Edelstein de Pesquisas Sociais.

Spink, M. J. P., \& Lima, H. (2013). Rigor e visibilidade: A explicitação dos passos da interpretação. In M. J. P. Spink (Org.), Práticas discursivas e produção de sentidos no cotidiano: Aproximações teóricas e metodológicas (pp. 93-122). Rio de Janeiro: Centro Edelstein de Pesquisas Sociais.

Spink, M. J. P., \& Medrado, B. (2013). Produção de sentidos no cotidiano. In M. J. P. Spink, Práticas discursivas e produção de sentidos no cotidiano: Aproximações teóricas e metodológicas (pp. 22-41). Rio de Janeiro: Centro Edelstein de Pesquisas Sociais.

Takadoro, D. C. (2012). Transtornos mentais na atenção primária: Uma reflexão sobre a necessidade de organizar e acolher a demanda dos usuários do SUS (Monografia, Universidade Federal de Minas Gerais, Uberaba, MG, Brasil). Recuperado de http://hdl. handle.net/1843/BUBD-9DEDXA

Tesser, C. D. (2006). Medicalização social (I): O excessivo sucesso do epistemicídio moderno na saúde. Interface, 10(19), 61-76. Recuperado de http://www.scielo.br/pdf/icse/v10n19/ a05v1019.pdf

Vidal, C. E. L., Yañez, B. de F. P., Chaves, C. V. S., Yañez, C. de F. P., Michalaros, I. A., \& Almeida, L. A. S. (2013). Transtornos mentais comuns e uso de psicofármacos em mulheres. Cadernos de Saúde Coletiva, 24(4), 457-464. Disponível em http://www.scielo.br/pdf/cadsc/v21n4/ v21n4a15.pdf

Von Korff, M., Dworkin, S. F., \& Le Resche, L. (1990). Graded chronic pain status: An epidemiologic evaluation. Pain, 40(3), 279-291. doi:https://doi.org/10.1016/0304-3959(90)91125-3

Recebido em: 10/01/2019 Última revisão: 04/12/2019

Aceite final: 25/04/2020

\section{Sobre as autoras:}

Josenaide Engracia dos Santos: Doutorado em Ciências da Saúde. Mestrado em Saúde Coletiva. Graduação em Terapia Ocupacional e Psicologia. Professora adjunta da Universidade de Brasília (UnB). Coordenadora do projeto de pesquisa sobre o Programa Mais Médicos, com financiamento do Conselho Nacional de Desenvolvimento Científico e Tecnológico (CNPq), do projeto de pesquisa de Saúde Integral de Atendimentos a Famílias Carentes de Ceilândia, coordena a Liga de Saúde 
da Família e Comunidade. Coordena pesquisa sobre Sofrimento Psíquico de Pretos e Pretas do Sol Nascente. E-mail: josenaidepsi@gmail.com, Orcid: http://orcid.org/0000-0002-7712-8470

Rozemere Cardoso de Souza. Doutorado e mestrado em Enfermagem Psiquiátrica pela Escola de Enfermagem de Ribeirão Preto da Universidade de São Paulo (USP). Graduação em Enfermagem. Líder do Grupo de Pesquisa em Saúde Mental e coordenadora adjunta do Centro Regional de Referência para Formação Permanente de Profissionais para o Enfrentamento do Crack e Outras Drogas, da Universidade Estadual de Santa Cruz (CRR/UESC). Professora titular (plena) da UESC. E-mail: rozemeresouz@ig.com.br, Orcid: http://orcid.org/0000-0003-2705-1556 
